DOI: 10.1515/pessr-2016-0020

\title{
Conceptualizing Leisure Within the Highly Regimented World of Elite Hockey
}
Authors' contribution:
A) conception and design of the study
B) acquisition of data
C) analysis and interpretation of data
D) manuscript preparation
E) obtaining funding

\author{
Bradley MacCosham \\ University of Ottawa, Canada
}

ABSTRACT

The purpose of this paper is to offer a conceptualization of leisure that can help us understand what constitutes as leisure and how leisure is attained in a highly regimented context such as elite hockey. Leisure researchers are unable to agree on a definition of leisure that best represents the field, which is perhaps why leisure has lost its significance within contemporary academia. In this paper, a conceptualization is provided that was developed through research on Junior level ice hockey players. Junior level hockey has a highly structured and professionalized regiment but yet, leisure is still attainable for players despite having little control over their involvement. Traditional definitions of leisure do not capture what it means to be in leisure even though theoretically Junior level hockey players are considered to be in serious leisure as amateurs. Thus, this paper can help justify and lets us understand how leisure is attained in Junior level hockey.

KEYWORDS leisure, behavior, capitalism, hockey

\section{Introduction}

Defining leisure has been and continues to be one of the most difficult tasks for leisure researchers. The inability to agree on a definition of leisure has sparked a number of arguments and debates between leisure theorists, which has ultimately left the field in an identity crisis (Rojek, 2010). The ongoing debate as to how leisure should be defined is perhaps one of the reasons why the field has lost some of its relevance and credibility within the world of academia (Rojek, 2010). Academic institutions with leisure programs are consistently seeing cutbacks in funding for research, the amount of courses being taught and instructors (Stebbins, 2011). In contemporary academia there are new and successful branches of research such as sports studies, event management and tourism studies, all of which used to fall under leisure studies (Rojek, 2010). The field of leisure has therefore become more integrated with other fields of research (Henderson, 2006; Stebbins, 2011); however, leisure studies needs to become more relevant if researchers want it to remain a separate field of study.

Defining leisure is not a simple task with some leisure scholars (Blackshaw, 2010; Henderson, Presley, $\&$ Bialeschski, 2004) going so far to say that it cannot be reduced to a simple definition and that researchers should stop trying to do define it. However, accepting this idea puts into question the relevance of leisure 
studies and the inability to define the fundamental basis of the field. This seems to be consistent with Rojek (2010), who argued that leisure researchers have not put forth a new definition for leisure in quite some time. Although some leisure scholars (Blackshaw, 2010; Henderson et al., 2004) no longer see the need in trying to define leisure, there are important implications to abandoning these efforts and for the field in general. If researchers do not acknowledge the limitations of working within a discipline without a definitional framework, it risks losing relevance in contemporary academia

In order to move forward as a researcher and as a discipline, some conceptual agreement is required. While it is certain that a finite definitional and/or conceptual framework for leisure may be improbable and could also be reductive, there remains a need to more concretely articulate what constitutes leisure and how it remains relevant for researchers studying human behavior. In my own research studying Junior level ice hockey as leisure, I faced questions as to how this level of amateur sport qualified as leisure, even in the most "serious" (Stebbins, 2015) sense of the word, because of its highly professionalized and regimented framework. This seemingly antiquated perception of leisure prompted me to revisit the seemingly endless debate about defining or not defining leisure to in part justify studying elite ice hockey as leisure, and to also justify why elite ice hockey was studied as leisure. Thus, the purpose of this paper is to offer my own conceptualization of leisure that can help us understand what constitutes as leisure and how leisure is attained in a highly regimented context such as elite hockey.

\section{The ongoing definitional dilemma of leisure}

Since leisure studies became a prominent field of research at the time of the industrial revolution, researchers have struggled with the meaning and definition of leisure. It comes as no surprise that researchers have used various approaches (e.g., subjective and objective, qualitative and quantitative, etc.) to study leisure in an attempt to better understand its meaning (Beatty, \& Torbert, 2003; Brightbill, 1960; Blackshaw, 2010; Dumazedier, 1974; Godbey, 1985; Howe, 1985; Kaplan, 1975; Kelly, 2012; Mannell, 1984; Mobily, 1989; Neulinger, 1981; Parker, 1976; Rojek, 1995; Shaw, 1985; Stebbins, 2005). Indeed, the definition of leisure has commanded the attention of many researchers, as it is the fundamental basis of the field. Yet, it seems as though little progress has been made to satisfactorily define leisure, as there is still no agreement between researchers on a single definition. While it is believed that leisure can be interpreted in various ways (Blackshaw, 2010), it is most commonly defined in terms of free time, activity and experience. The dilemma then finds itself in how these different approaches relate to one another and how they are all defining the same thing.

As mentioned, leisure research began to strive during the industrial revolution when society was concerned with how individuals spent their free time after work. During this time working schedules became more structured with clear hours at work versus time off. In other words, time off became as scheduled as work and people were looking for ways to fill this predictable free time. Leisure was understood as being antithetical to work, which reflected the industrialized view of the world where work was scheduled first and everything else was considered free time, or leisure (Robinson, \& Godbey, 1997). Thus, leisure was simply understood by researchers as free time away from work (Clawson, \& Knetsch, 1974; Gist, \& Fava, 1964; Lundberg, Komarovsky, \& McInnery, 1934). Although this was a simple way for understanding leisure that could be easily identified and objectively measured by researchers, the simple dichotomy between work and leisure was problematized, as it ignored the intrinsic desire to pursue activities during free time (Kelly, \& Godbey, 1992). Researchers recognized that certain activities that consumed peoples free time were as obligated and necessary for survival as work (e.g., eating, sleeping, cleaning, etc.) and could therefore not constitute as leisure. Instead, researchers categorized those types of activities as non-work obligations or disagreeable obligations along with work (Brightbill, 1960; Fairchild, 1970; Giddens, 1964; Kelly, 1972; Elkington, \& Stebbins, 2014; Stebbins, 2015). Thus, the concept of leisure as free time was largely reduced to the time taking place after any form of disagreeable life obligation, be it work or non-work. This seemed to be consistent with Brightbill's definition of leisure: 
"a block of unoccupied time, spare time, or free time when we are free to rest or do what we choose. Leisure is time beyond that which is required for existence, the things which we must do, biologically, to stay, alive (that is, eat, sleep, eliminate, medicate, and so on): and subsistence, the things we must do to make a living as in work, or prepare to make a living as in school, or pay for what we want done if we do not do it ourselves. Leisure is time in which our feelings of compulsion should be minimal. It is discretionary time, the time to be used according to our own judgment or choice" (Brightbill, 1960, p. 4).

Although researchers understood leisure as time after disagreeable obligations, the question still remained as to what individuals were actually doing during their free time. This question became the foundation of activity-based definitions of leisure, which meant that leisure was no longer solely defined in terms of free time. Instead, researchers began to define leisure as freely chosen activities voluntarily pursued during time after obligations necessary for survival (Neumeyer, \& Neumeyer, 1958; Parker, 1976; Stebbins, 2015). This seemed to have inspired Parker's (1976) definition of leisure as the "time free from work and other obligations, it also encompasses activities which are characterized by a feeling of comparative freedom" ( $p$. 48), which emphasized both free time and activity. Similarly, Stebbins (2015, p. 3) defined leisure as an "uncoerced, contextually framed activity engaged in during free time, which people want to do and, using their abilities and resources, actually do in either a satisfying or a fulfilling way".

While the activity-based approach has been significant to the field and is still an important approach used today, researchers have pointed out its limitations. Freedom and free choice are the central components of the activity-based approach; however, the notion of freedom has been criticized as a means for defining leisure (Rojek, 1995, 2010). It has been argued that the idea of freedom is a social construct that is an illusion in our modern and capitalist society (Rojek, 1995). Individuals are unknowingly under many constraints imposed on them by society and forced to comply with societal norms and expectations (Rojek, 1995). Similarly in leisure, an individual's behavior is often subject to manipulation and exploitation by capitalists (Rojek, 1995). The capitalist will exploit individuals based on their behavior patterns, which does not reflect the idea of freedom or free choice (Rojek, 1995). This can be exemplified by consumerism, which has led to the commodification and shaping of leisure practices in capitalist societies (Rojek, 1995). Thus, the notion of freedom seems to be unsuitable for defining leisure, which has put into question many researchers' understanding of leisure.

Another shortcoming of the activity-based approach is that it makes no reference to the individual's experiences when participating in leisure activities (Blackshaw, 2010). Thus, leisure has taken on another meaning, as researchers began to focus on the experiential qualities of leisure. As a result, researchers developed the experience-based approach for defining leisure. Historically, as well as in current research, researchers who have focused on the experiential qualities of leisure have associated it with profound experiences such as self-development, spiritual inquiry, self-actualization and personal reflection (Beatty, \& Torbert, 2003; Blackshaw, 2010; Dumzaedier, 1974; Gist „\& Fava, 1964; Godbey, 1985; Gray, 1971; Kaplan, 1975; Rigby, 1989). For example, Beatty and Torbert (2003, p. 243) defined leisure as "the experiential quality of our time when we engage voluntarily and intentionally in awareness-expanding inquiry, which in turn generates ongoing, transforming development throughout adulthood". Similarly, Kaplan defined leisure as:

"leisure consists of relatively self-determined activity-experience that falls into one's economically free-time roles, that is seen as leisure by participants, that is psychologically pleasant in anticipation and recollection, that potentially covers the whole range of commitment and intensity, that contains characteristic norms and constraints, and that provides opportunities for recreation, personal growth and service to others" (Kaplan, 1975, p. 26).

Researchers who take this approach draw on traditional definitions from the ancient Greeks, who saw leisure as "an activity generated by an inner attitude of voluntary engagement and inquiry" (Beatty, \& Torbert, 2003, p. 241). One of the benefits of defining leisure in terms of experience is that it acknowledges the presence of constraints as being a part of certain leisure practices (Blackshaw, 2010; Kaplan, 1975). In addition, some 
researchers have lifted the barrier between work and leisure, as they acknowledge that leisure is an experience that could take place at any time and any place, including work (Beatty, \& Torbert, 2003; Kelly, 2012). The experiential approach also recognizes that leisure activities can be work like and work can be leisurely (Beatty, \& Torbert, 2003).

Defining leisure as experience has become increasingly popular in recent years, however, there is an important shortcoming to this approach as well. The main issue with this approach for defining leisure is that it makes leisure something that is elitist. Researchers (Mobily, 1989; Podilchak, 1991; Shaw, 1985) have found that the most common experiences that individuals associate with leisure are fun, relaxation, pleasure, enjoyment, entertainment, etc., which ultimately raises the question as to how common it is to have profound experiences in daily life. Defining leisure as profound experiences could eliminate or drastically reduce the possibility to conduct leisure research, as it is quite difficult for researchers to do research on or pinpoint experiences that hardly ever occur. This is in addition to describing these types of experiences as being indefinable (Blackshaw, 2010). Thus, if a researcher cannot adequately justify what constitutes a profound leisure experience, it becomes impractical to conduct research on those experiences. This has subsequently led to discrepancies between experience-based researchers themselves, as they continue to contemplate what experiences actually constitute leisure. For example, some researchers associate leisure with pleasurable experiences such as self-actualization, fun, relaxation, etc. (Blackshaw, 2010; Kaplan, 1975; Mobily, 1989; Podilchak, 1991; Shaw, 1985) while others acknowledge that pleasurable experiences are not always a part of leisure and that leisure can be associated with fatigue, apprehension, stage fright, guilt, etc. (Lee, Dattilo, \& Howard, 1994; Elkington, \& Stebbins, 2014; Stebbins, 2015). It seems as though researchers from this school of thought find themselves within their own definitional dilemma, as experience-based researchers have yet to agree on an experiential definition of leisure. Consequently, leisure has become something that is indefinable (Henderson et al., 2004; Lee et al., 1994) and believed to be something that is a mystery, yet everybody seems to experience it (Blackshaw, 2010).

It is clear that leisure researchers are at an impasse when it comes to defining leisure, as providing new definitions has come to a standstill in recent years. Perhaps the reason for this definitional dilemma the field finds itself in is that researchers have turned leisure into something far more complicated than what it really is (Podilchak, 1991). While the definition and meaning of leisure has continuously been problematized, researchers still find themselves defining it either as free time, activity or experience. Perhaps the question then is what do these different approaches mean for the field of leisure? Researchers are using definitions that bare no similarity with one another, which makes it difficult to understand how they are all defining the same thing. The field seems to accept the idea that there are many ways to interpret the meaning of leisure, which has allowed researchers to comfortably choose any definition they please when designing their studies. Researchers now find themselves within a broader dilemma, that is, to continue working using definitions that misrepresent the field of leisure studies or reach a consensus on a definition that will represent the field of leisure studies.

\section{Re-conceptualizing leisure}

Although the meaning of leisure is something that has perplexed many researchers, it can be interpreted quite simply. Leisure is autonomous and intrinsic behavior when engaging in or acting towards an activity. In this definition, the individual determines if they are in leisure or not based on their perception of what they are doing when participating in an activity. Thus, if an individual approaches an activity or certain activities within a context as leisure, the individual is experiencing leisure. Additionally, the element of autonomy within this definition of leisure represents the individual's capacity to behave and act in a way that is perceived to be on his or her own terms. When in leisure, the individual has very little awareness of the presence of constraints, which allows them to act in a way that is perceived to be autonomous and intrinsic. The individual in leisure is not concerned and will not be influenced by the constraints imposed on them. While I emphasize leisure as being autonomous behavior where the individual is relatively free of constraints, I am not necessarily 
eliminating nor am I ignoring the presence of constraints altogether. Rather, I am merely expressing that leisure allows individuals to perceive themselves as being autonomous and having a sense of control over their behavior and actions despite the presence of constraints.

Furthermore, through autonomous and intrinsic behavior individuals have the feeling of being in control of the outcome (i.e., their experiences) of their involvement in an activity. The individual who is able to optimize his or her experience(s) when engaged in an activity will attach a greater meaning to their experience(s). Consequently, the individual who attaches a greater meaning to their experience in an activity will be more compelled to engage in it. Thus, leisure has the capacity to establish and solidify relationships between experiences and activities. Through this process, I believe that it is possible for individuals to enhance their quality of life and well-being, as they will behave in a way that is beneficial for them rather than someone else. Not only do I believe that leisure is beneficial for the individual, but it can also have implications beyond those experienced by them personally. For example, in the context of work, the employee who attaches a greater meaning to their job is perhaps more likely to perform and produce to the expectations of their employer. The employee who is in leisure at the workplace has a decreased perception of the constraints imposed on them by their superiors and act intrinsically to accomplish his or her given tasks. The employee in this situation is working to achieve a desired experience through their intrinsic behavior to accomplish given tasks, while their productivity will satisfy their employer.

While the argument has already been put forth that freedom cannot be associated with leisure (Rojek, 1995, 2010), this definition speaks more towards preserving human agency rather than labeling individuals as being free. This is consistent with the concepts of liquid modernity and liquid leisure where it is the individual who has authority over their actions and involvement in leisure practices in modern society (Blackshaw, 2010). Liquid leisure insists that the individual is not subject to top down authority when participating in an activity and has control over their engagement in an activity (Blackshaw, 2010). Similar comparisons can be drawn from Marx (1977) who also conceptualized leisure by eliminating the concept of free choice, while preserving human agency. Marx explained that

"men make their own [leisure], but they do not make it just as they please; they do not make it under circumstances chosen themselves, but under circumstances directly encountered, given, and transmitted from the past" (Marx, 1977, p. 300).

This theory is mainly comparable to Marx’s (1964) discussion on the relationship between laborers and capitalists. In the capitalist society we find ourselves within focus is generally on productivity, which has led to the alienation of laborers. Tasks are imposed on laborers, which forces them to invest their energy towards work to satisfy their owner's capital. As a result, the process of work is experienced externally to the laborer (Marx, 1964). The product of labor does not belong to the individual, as they are forced to create value through the act of labor, which is then benefited by the capitalist rather than the laborer (Rojek, 1995).

Although Marx's discussion mainly focuses on the alienation of laborers, Rojek (1995) discussed that the consumption of leisure is affected in parallel. He explained that leisure experiences are coerced and manipulated by capitalists who package and produce leisure experiences external to the individual who consumes it. Leisure experiences benefit the capitalist who provided the service and opportunity to pursue leisure, which bares similarities to the laborers experience. However, my conceptualization of leisure insists that the individual who is in leisure has the capacity to create value through their behavior, which is benefited by the individual despite the implications their experiences have for capitalists and the leisure industry. Although the individual is subject to manipulation by capitalists who exploit consumer behavior, the individual in leisure does not perceive this. Rather, the individual in leisure acts in their best interest even though they are unknowingly benefiting the capitalist industry.

Recent theories have also described leisure in a similar fashion, for example, Stebbins (2015) emphasized that leisure is uncoerced behavior, that is, leisure is based on the intention to participate and what people want to do. However, Stebbins (2015) seems to contradict himself with his conceptualization of leisure. 
While he emphasized that the central aspect of leisure is uncoerced behavior, he also defined leisure in terms of activity pursued during free time. In addition, he referred to leisure as being something that is positive for the individual and society as a result, which implies that leisure is a means for social control (Blackshaw, 2010). Thus, Stebbins' (2015) interpretation of leisure contrasts with my own, since my conceptualization reflects the individual's resistance towards social control rather than complying with societal norms and expectations. The example I have provided on the employee in the workplace is perhaps a representation of how leisure could be positive, but this is not always the case with my understanding of leisure. Leisure could lead to negative outcomes for the individual and society as well, for example, those who engage in deviant or criminal activities may very well be in leisure but be punished for their behavior. These individuals could also cause a great deal of damage through their behavior, which could be harmful to themselves and others in their surroundings.

Another important component in my conceptualization of leisure is how experiences can render meaning to an activity. This quality is mainly inspired by the symbolic interactionism framework, which focuses on how meaning is given to an activity based on the individuals experiences when participating in it (Hewitt, 2000). Typically, meaningful experiences are a result of social interaction and meanings of experiences are modified through an interpretive process (Hewitt, 2000). However, what will determine the quality of the individual's experiences in an activity is ultimately their intrinsic desire to participate in it. The intrinsic aspect is crucial for determining the quality of experiences, as an individual who has no desire to participate in an activity is less likely to be engaged in it when participating. In contrast, if an individual approaches or perceives that they are in leisure when participating, it is more likely that the individual will have meaningful experiences and attach greater meaning to the activity.

Similar comparisons can be made with Stebbins' (2015) serious leisure-casual leisure dichotomy where the individual who is engaged in an activity will experience significant benefits, while the individual who is moderately engaged may not be as rewarded (Elkington, \& Stebbins, 2014). Although Stebbins' (2015) framework is referenced here, I am not dichotomizing activities as either serious or casual, as I believe the same benefits can be experienced in any type of pursuit. The comparison simply lies in the different levels of intensity when engaged (or disengaged) in an activity. An individual who is in leisure is more likely to attach significant experiences to an activity, while an individual who associates an activity with work or restraint may attach the activity to less significant experiences (Stebbins, 2015). While experience and activity have important implications in my theory, it is important to note that the process of linking meaningful experiences to activity is merely a product of leisure and not leisure itself. However, the symbolic interactionism approach would be an appropriate methodological framework for understanding the experiences produced through leisure behavior.

Furthermore, my theory insists that autonomous and intrinsic behavior is fundamental for an individual to be in leisure. Therefore, I must acknowledge its similarities with Deci and Ryan's (2000) self-determination theory. Self-determination theory explains how individuals will engage in activities to satisfy their basic psychological needs for autonomy, competence and relatedness to others. In addition, an activity will become internalized into ones identity when the activity becomes meaningful to them (Deci, Eghrari, Patrick, \& Leone, 1994). Self-determination theory also emphasizes that individuals participate in activities if they are intrinsically motivated to participate in them rather than being compelled to participate by external rewards (Vallerand, Deci, \& Ryan, 1987).

Although self-determination theory seems to encompass the qualities of leisure as I have described it, leisure is considerably different. Self-determination theory allows us to understand why an individual will continuously pursue an activity; while leisure allows us to understand how an individual regulates their behavior when acting towards or when engaged in an activity. Leisure allows us to understand how an individual is able to get the most out of their experiences in an activity despite the circumstances they find themselves in or the constraints imposed on them. Intrinsic behavior in leisure does not refer to a level of motivation per se, it refers to the desire to behave in a way that is not coerced or manipulated based on the perception of the individual's and the context they are in. 


\section{Junior level ice hockey}

Now that a definition of leisure has been established, I can relate it to the original question of the paper, which was how Junior hockey constitutes as leisure. Junior level hockey is usually a stepping-stone before a hockey player reaches professional and/or university/collegiate (e.g., NCAA) level hockey. As a means for preparing players to make the transition into higher levels of play, Junior hockey has a highly regimented and professionalized framework. Typically, Junior hockey players are on the ice either practicing or playing games up to six days a week along with daily (or almost daily and sometimes even twice-daily) off-ice training sessions. Players are required to dedicate the majority of their time and energy towards the pursuit of hockey in order to enhance their skills and knowledge in the sport. Players are expected to perform at their highest ability in practices and games if they wish to keep their place on the team. If players fail to perform to the expectations of the coach and/or organization, coaches will punish players in various ways, such as reducing their playing time, sitting them out of games, force them to take part in grueling skating drills in practice, they may trade them to another organization, and could release them from the team leaving players responsible for finding another team to play for if they can, to name a few. Some players will be on a meal plan and have to weigh themselves regularly in front of team trainers at different times during the season. This is intended for players to gain the necessary weight and muscle mass to compete in Junior hockey. In addition, players usually have a curfew the night before games to assure that they save their energy for the game the following day. Thus, players are under the complete control and authority of their organization the moment they sign their contract and claim their spot on the team. They work for their organization, which operates in a business-like manner. In fact, there have even been efforts to unionize Junior hockey players because of the work-like conditions they must comply with (TSN, 2016).

While Junior hockey players can be compared to laborers, theoretically they can also be classified as serious leisure pursuers. Junior hockey players are non-professional athletes and labeled as amateurs. They are there because they want to, the primary goals of serious leisure are to train and perform. They reflect the six characteristics of serious leisure (i.e., unique ethos, leisure career, durable benefits, personal effort, perseverance, identification). And, the activity is a central aspect of their life that requires a significant amount of personal investment (Elkington, \& Stebbins, 2014). However, even though the serious leisure framework can be used to exemplify these players' experiences in Junior hockey, it does not adequately represent what these players are actually going through. Junior level hockey can by no means be classified as serious leisure.

Players have no control over their involvement or many aspects of their life when in Junior hockey. Similar comparisons can be made between Junior level hockey players and Marx's (1964) discussion on the alienation of laborers. Players are under the direct authority of their capitalist (i.e., coaches, organization) and are required to invest most of their energy towards the pursuit of hockey to satisfy their owners capital, as do laborers. As a result, the experiences players have in Junior hockey are not their own, rather, they are external and aimed to benefit the organization they play for. Players' experiences are manipulated and coerced by coaches and the organization through their hard work in practice and training sessions, which is designed to improve their productivity in games. The player does not benefit from his success in Junior hockey, rather, it is the organization that does by developing a winning reputation, having people come watch their team play, keeping their team in the community and the coaches/managers won't be fired if their team is successful.

But the question still remains as to how this highly regimented and often dehumanizing context can be a site where leisure is still experienced? As mentioned earlier, experienced when an activity is intrinsically pursued and performed autonomously. There are certain players who do not perceive themselves as being under the authority of their organization and perceive themselves as having complete autonomy over their involvement in Junior hockey. These players welcome the demands placed before them and fully invest themselves to the pursuit of hockey without any hesitation.

While it is certain that not all players behave this way or perceive themselves as being in complete control over their involvement in Junior hockey, leisure can still be attained through $\mathrm{m}$ any aspects of their participation in the sport. For example, players may be in leisure in the dressing room when bantering amongst 
each other. In those instances, players have a significant amount of perceived autonomy over their behavior and often engage intrinsically in conversations in the dressing room, which are also some of the most cherished moments players have. While players are technically still under the authority of the coach and organization during this time, they are able to act autonomously more so than in other instances. There are many other instances where a player could attain leisure in Junior level hockey. For example, when players are performing on the ice during a game they are in control over their actions and could associate meaning to their time performing. If a player enjoys fighting they could also be in leisure based on their behavior, as they have control over their behavior to engage in a fight and has associated meaning to fighting as a result.

\section{Conclusion}

This paper has important implications. This paper offers a unique contribution to the meaning of leisure. Indeed, the description of leisure provided in this paper touches on certain aspects that have already been discussed in past literature, however it remains different from them. The most important aspect of leisure described in this paper is autonomous and intrinsic behavior, which preserves human agency in a society that has control over our behavior. While it is evident that individuals are consistently under societal constraints, it is their perceived autonomy that is crucial for understanding an individual's behavior when engaged in an activity. This paper also has implications for understanding human behavior in general. Leisure helps us understand how an individual guides their behavior when engaging in activities and how it influences their experiences when participating in them. This paper also allows us to understand why individuals engage in certain contexts that are considered dehumanizing, deviant, controversial, etc. Lastly, this paper has methodological implications. While leisure remains subjective in my conceptualization, researchers can certainly identify when individuals are in leisure when engaged in an activity, which would be when an individual perceives themselves as being in control of their behavior and actions. Researchers could then explore how the different experiences associated with leisure. This paper is an attempt at providing a definition of leisure that is different, yet still relatable to previous definitions. It is hopeful that this paper captures the attention of scholars in the field to build or expand on this theory.

The limitations of this paper must be acknowledged. The main limitation is that this paper is theoretical and has yet to be supported with empirical data. Future research should apply this framework to see if it represents an individual's involvement in an activity. Future studies should also apply this framework using various contexts and sample populations to assert its credibility.

\section{REFERENCES}

Beatty, J.E., \& Torbert, W.R. (2003). The False Duality of Work and Leisure. Journal of Management Inquiry, 12(3), 239-252. Doi:10.1177/1056492603256340

Blackshaw, T. (2010). Leisure (Key Ideas). New York, NY: Routledge.

Brightbill, C.K. (1960). The Challenge of Leisure. Englewood Cliffs, NJ: Prentice-Hall.

Clawson, M., \& Knetsch, J.L. (1974). Leisure in Modern America. In J. F. Murphy (Ed.) Concepts of Leisure. Englewood Cliffs, NJ, Prentice-Hall, 78-90.

Deci, E.L., Eghrari, H., Patrick, B.C., \& Leone, D.R. (1994). Facilitating internalization: The self-determination theory perspective. Journal of Personality, 62(1), 119-142. Doi:10.1111/j.1467-6494.1994.tb00797.x

Deci, E.L., \& Ryan, R.M. (2000). The "what" and "why”' of goal pursuits: Human needs and the self-determination of behavior. Psychological Inquiry, 11(4), 227-268. Doi:10.1207/S15327965PLI1104_01

Dumazedier, J. (1974). Leisure and The Social System. In J. F. Murphy (Ed.) Concepts of Leisure. Englewood Cliffs, NJ: Prentice-Hall.

Elkington, S., \& Stebbins, R.A. (2014). The serious leisure perspective: An introduction. New York, NY: Routledge. Fairchild, H. (1970). Dictionary of Sociology. Westport, CN: Greenwood Press.

Giddens, A. (1964). Notes on the concept of play and leisure. Sociological Review, 12(1), 73-89. Doi:10.1111/j.1467954X.1964.tb01247.x 
Gist, N.P., \& Fava, S.F. (1964). Urban Society. New York, NY: Crowell.

Godbey, G. (1985). Leisure in Your Life. State College, PA: Venture.

Gray, D.E. (1971). This Alien Thing Called Leisure. Paper presented at Oregon State University, Corvallis, Oregon, 8 July, quoted in J. F. Murphy (Ed.) Concepts of Leisure. Englewood Cliffs, NJ: Prentice-Hall.

Henderson, K.A. (2006). False Dichotomies and Leisure Research. Leisure Studies, 25(4), 391-395. Doi:10.1080/02614360600896387

Henderson, K.A., Presley, J., \& Bialeschki, M.D. (2004). Theory in recreation and leisure research: Reflections from the editors. Leisure Sciences, 26(4), 411-425. Doi:10.1080/01490400490502471

Hewitt, J.P. (2000). Self and society: A symbolic interactionist social psychology ( $8^{\text {th }}$ ed.). Needham Heights, MA: Allyn and Bacon.

Howe, C. (1985). Posibilities for Using A Qualitative Research Approach in The Sociological Study of Leisure. Journal of Leisure Research, 17(3), 212-224.

Kaplan, M. (1975). Leisure: Theory and practice. New York, NY: John Wiley.

Kelly, J.R. (1972). Work and leisure: A simplified paradigm. Journal of Leisure Research, 4(1), 50-62.

Kelly, J.R. (2012). Leisure (4 ${ }^{\text {th }}$ ed.). Urbana, IL: Sagamore Publishing.

Kelly, J.R., \& Godbey, G. (1992). The Sociology of Leisure. State College, PA: Venture Publishing.

Lee, Y., Dattilo, J., \& Howard, D. (1994). The Complex and Dynamic Nature of Leisure Experience. Journal of Leisure Research, 26(3), 195-211.

Lundberg, G., Komarovsky, M., \& McInnery, M.A. (1934). Leisure: A suburban study. New York, Columbia University Press.

Mannell, R.C. (1984). A Psychology for Leisure. Society and Leisure, 7(1), $13-21$. Doi:10.1080/07053436.1984.10715168

Marx, K. (1964). Economic and Philosophic Manuscripts. New York, NY: International Press.

Marx, K. (1977). Karl Marx: Selected writings (D. McClellan, ed.). Oxford: Oxford University Press.

Mobiliy, K. (1989). Meanings of Recreation and Leisure Among Adolescents. Leisure Studies, 8(1), 11-23. Doi:10.1080/02614368900390021

Neulinger, J. (1981). The Psychology of Leisure (2 ${ }^{\text {nd }}$ ed.). Springfield, IL: Charles C. Thomas.

Neumeyer, M.H., \& Neumeyer, E.S. (1958). Leisure and Recreation. New York, NY: Ronald Press.

Parker, S. (1976). The Sociology of Leisure. London, Allen \& Unwin.

Podilchak, W. (1991). Distinctions of Fun, Enjoyment and Leisure. Leisure Studies, 10(2), 133-148. Doi:10.1080/02614369100390131

Rigby, B. (1989). French intellectuals and leisure: The case of Emmanuel Mounier. In T. Winnifrith \& C. Barrett (Eds.), The philosophy of leisure (pp. 160-171). New York: St. Martin's.

Robinson, J., \& Godbey, G. (1997). Time for life: The surprising ways Americans use their time. University Park: Pennsylvania State University Press.

Rojek, C. (1995). Decentring leisure: Rethinking leisure theory. Thousand Oaks, CA: Sage Publications.

Rojek, C. (2010). Leisure and emotional intelligence: A response to my commentators. World Leisure Journal, 52(4), 274-278. Doi:10.1080/04419057.2010.9674652

Shaw, S.M. (1985). The Meaning of Leisure in Everyday Life. Leisure Sciences, 7(1), 1-24. Doi:10.1080/01490408509512105

Stebbins, R.A. (2005). Choice and Experiential Definitions of Leisure. Leisure Sciences, 27(4), 349-352. Doi:10.1080/01490400590962470

Stebbins, R.A. (2011). Leisure studies: The road ahead. World Leisure Journal, 53(1), 3-10. Doi:10.1080/04419057.2011.552197

Stebbins, R.A. (2015). Leisure and positive psychology: Linking activities with positiveness. New York, NY: Palgrave Macmillan

TSN (2016). Westhead: CHL boss stands strong against players' union. Retrieved from: http://www2.tsn.ca/chl/story/?id=460273

Vallerand, R.J., Deci, E.L., \& Ryan, R.M. (1987). Intrinsic Motivation in Sport. Exercise and Sport Sciences Reviews, 15(1), 389-425. 
AUTHOR'S ADDRESS: $\quad$ Brad MacCosham

1320 Inge Crescent

Navan, Ontario, Canada

K4B 1M7

E-mail: bmacc067@uottawa.ca

Received: 22 April 2016; Accepted: 22 June 2016 